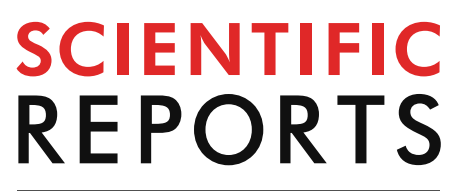

natureresearch

Check for updates

\title{
OPEN The synergistic interaction of thermal stress coupled with overstocking strongly modulates the transcriptomic activity and immune capacity of rainbow trout (Oncorhynchus mykiss)
}

Alexander Rebl ${ }^{1}$, Tomáš Korytáŕ ${ }^{2}$, Andreas Borchel ${ }^{3}$, Ralf Bochert ${ }^{4}$, Joanna Ewa Strzelczyk ${ }^{5}$, Tom Goldammer ${ }^{1,6}$ \& Marieke Verleih ${ }^{1 \bowtie}$

The objective of the present study is to identify and evaluate informative indicators for the welfare of rainbow trout exposed to (A) a water temperature of $27^{\circ} \mathrm{C}$ and (B) a stocking density of $100 \mathrm{~kg} /$ $\mathrm{m}^{3}$ combined with a temperature of $27^{\circ} \mathrm{C}$. The spleen-somatic and condition index, haematocrit and the concentrations of haemoglobin, plasma cortisol and glucose revealed non-significant differences between the two stress groups and the reference group 8 days after the onset of the experiments. The transcript abundance of almost 1,500 genes was modulated at least twofold in in the spleen of rainbow trout exposed to a critical temperature alone or a critical temperature combined with crowding as compared to the reference fish. The number of differentially expressed genes was four times higher in trout that were simultaneously challenged with high temperature and crowding, compared to trout challenged with high temperature alone. Based on these sets of differentially expressed genes, we identified unique and common tissue- and stress type-specific pathways. Furthermore, our subsequent immunologic analyses revealed reduced bactericidal and inflammatory activity and a significantly altered blood-cell composition in challenged versus non-challenged rainbow trout. Altogether, our data demonstrate that heat and overstocking exert synergistic effects on the rainbow trout's physiology, especially on the immune system.

Stressors in aquaculture cover a broad and diverse range of abiotic and biotic factors including inappropriate temperature, oxygen content, salinity, $\mathrm{pH}$ value, high doses of ultraviolet light, inorganic and organic substances, conspecific competition and predators. The co-occurrence of multiple stressors in aquaculture facilities ${ }^{1-3}$ has various physiologic consequences for the farmed fish ranging from moderate alterations at the molecular level to increased disease susceptibility, behavioural disorders or even mortalities ${ }^{3-5}$. It is well established that adverse

${ }^{1}$ Institute of Genome Biology, Leibniz Institute for Farm Animal Biology (FBN), Wilhelm-Stahl-Allee 2, 18196 Dummerstorf, Germany. ${ }^{2}$ Institute of Aquaculture and Protection of Waters, Faculty of Fisheries and Protection of Waters, University of South Bohemia, Husova tř. 458/102, 37005 České Budějovice, Czech Republic. ${ }^{3}$ Sea Lice Research Centre (SLRC), Department of Biology, University of Bergen, Thormøhlensgate 55, 5008 Bergen, Norway. " Institute of Fisheries, State Research Centre of Agriculture and Fisheries, Mecklenburg-Vorpommern (LFA-MV), Südstraße 8, 18375 Born, Germany. ${ }^{5}$ Institute of Immunology, Federal Research Institute for Animal Health, Friedrich-Loeffler-Institute, 17493 Greifswald-Insel Riems, Germany. ${ }^{6}$ Faculty of Agriculture and Environmental Sciences, University of Rostock, 18059 Rostock, Germany. ${ }^{\square}$ email: verleih@ fbn-dummerstorf.de 
environments involving multiple stressors provoke a status of immunosuppression ${ }^{6-8}$ related to severe consequences for aquaculture industry ${ }^{9-12}$. In essence, steroid hormones and neuroamines transfer the stress signals and impair a variety of immune functions ${ }^{13-15}$, including the reduced viability, proliferation and migration of immune-cell populations ${ }^{16}$, limited phagocytic activity and decreased production of pro-inflammatory mediators and antibodies ${ }^{17-19}$. These exogenously induced disturbances of the fishes' homeostasis are reflected in various physiological alterations such as changed concentrations of plasma proteins or the altered expression of specific genes.

For decades, numerous scientific studies have been concerned with the recording and assessment of stressinduced species-specific responses to find objective criteria that allow for the evaluation of an anthropogenic husbandry environment and development of guidelines for managing aquaculture facilities. Most of those studies focussed on the identification of potential biomarker genes and signalling pathways related to one particular stressor. In this regard, Oncorhynchus spp., which includes both Pacific salmon and trout, is one of the most investigated fish genera ${ }^{20}$. Particularly, the rainbow trout is not only a model species for immunological and toxicological studies but has been exposed, for instance, to a variety of challenging temperatures. While the thermal preference of this genus is well below $20^{\circ} \mathrm{C}^{21}$, the experiments included ice-cold temperatures ${ }^{22}$, moderately challenging temperatures of $18-23^{\circ} \mathrm{C}^{23-27}$ and critical temperatures of $25-28{ }^{\circ} \mathrm{C}^{28-30}$. Concerning crowding, different stocking densities up to $120 \mathrm{~kg} / \mathrm{m}^{3}$ were investigated over different periods ${ }^{31-36}$. Taken together, the resulting data sets document that individual challenge factors produce distinct and only slightly overlapping molecular signatures. Although multiple studies ${ }^{37-41}$ addressed the impact of simultaneously changing environmental conditions on the physiology of bony fish, only a few studies integrated a broader and complementing panel of phenotypic, plasma- and transcript-based parameters. As transcriptomic analyses detect the entirety of modulated gene expressions and affected signalling pathways, they help to understand whether concurrent stressors evoke additive, synergistic or even antagonistic effects at the molecular level.

The present study addresses the question whether the combination of critical temperature and overstocking evokes a stress response in rainbow trout. Our major goal was to identify novel potential biomarkers and induced functional pathways which provide sufficient information to identify improper husbandry conditions of rainbow trout. Using separate experimental approaches in our previous studies, we investigated the impact of adverse temperature ${ }^{23,27}$ and different stocking densities ${ }^{36}$ on rainbow trout. This current study followed a similar experimental design, but we exposed rainbow trout simultaneously to a critical water temperature and crowding. A water temperature of $27^{\circ} \mathrm{C}$ was chosen as the primary challenge factor. In the summer months of recent years, this temperature was repeatedly measured in the German coastal regions along the Baltic Sea where rainbow trout are bred for commercial and research purposes (Suppl. Fig. 1). The increase in water temperature is likely a consequence of global warming. An increased stocking density of $100 \mathrm{~kg} / \mathrm{m}^{3}$ was selected as the secondary challenge factor. This stocking density represents the upper limit for the conventional production of rainbow trout of respective age and weight as recommended by the Food and Agriculture Organisation of the United Nations ${ }^{42}$. Our previous investigations on the impact of crowding on rainbow trout revealed that a stocking density of $120 \mathrm{~kg} / \mathrm{m}^{3}$ significantly modulated the transcriptome of stress-relevant organs ${ }^{36}$ in comparison with those of trout kept at an uncrowded density ${ }^{33}$ of $30 \mathrm{~kg} / \mathrm{m}^{3}$, which corresponds approximately to the density recommended for the organic aquaculture of trout (Commission Regulation (EC) No 710/2009 of 5 August 2009, Appendix XIIIa).

To investigate how a challenge-induced response influences the immune system, we focused on the major immune organs: the spleen, head kidney and peripheral blood leukocytes. The spleen was selected for transcriptomic analysis as it is a major secondary lymphoid organ that represents the "meeting point" for pathogens and immune cells and is thus characterised by a generally remarkable magnitude of responses ${ }^{43-45}$. The head kidney plays a central role in the haematopoiesis of fish, also as a major reservoir of myeloid cells, which act as first responders upon pathogenic invasion ${ }^{46-48}$. The head kidney's ability to eliminate pathogens and orchestrate inflammatory responses has previously been studied under various conditions (diets and exposure to stressors and pathogens) as a reference for the immunocompetence and was investigated here in vitro after stimulation with the model pathogen Aeromonas salmonicida. Furthermore, we studied the composition of major subpopulations of circulatory leukocytes, which reflect the physiological and pathological stress-induced changes.

\section{Results}

Characterisation of the response to heat and crowding based on condition indices and blood parameters. Using a multi-parametric approach on rainbow trout cultivated in recirculating aquaculture system (RAS) tanks, we assessed the effects of a critical temperature (gradual temperature increase up to $27^{\circ} \mathrm{C}$; hereafter referred to as the thermal-challenge group B) compared to the combined effects of critical temperature and crowding (gradual temperature increase up to $27^{\circ} \mathrm{C}$ at a stocking density of $100 \mathrm{~kg} / \mathrm{m}^{3}$; hereafter referred to as combined-challenge group C) (Fig. 1). We determined the condition score, spleen-somatic index and haematocrit (Fig. 2A-C) and recorded the traditional and relatively fast detectable parameters of haemoglobin, cortisol and glucose concentration in the blood of rainbow trout (Fig. 2D-F) under challenging versus control conditions. Each of these tests revealed non-significant differences between the challenge groups $\mathrm{B}$ and $\mathrm{C}$ and the reference group A.

Gene-expression profiling in the spleen of trout exposed to critical temperature. We detected a strong influence of both challenging conditions on the gene expression in the spleen. In total, the transcript abundance of almost 1,500 genes was modulated at least twofold for rainbow trout exposed to a high temperature alone or a high temperature combined with crowding as compared to the reference fish (Fig. 3A; Gene Expression Omnibus (GEO) accession code: GSE129271). 


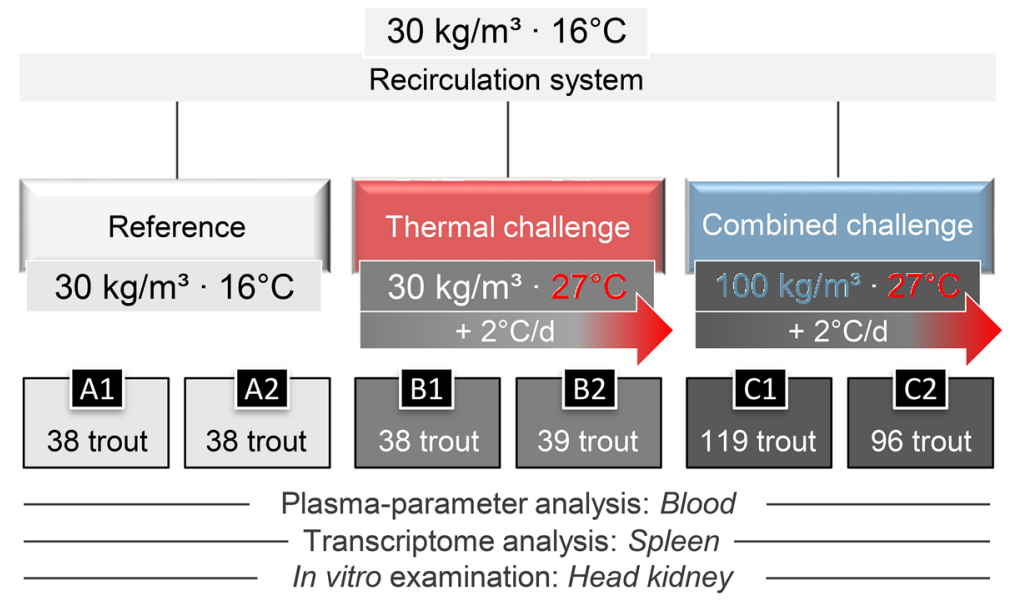

Figure 1. Schematic representation of the challenge experiment conducted on 368 rainbow trout. The total number of trout per experimental tank is indicated. In the reference tanks A1 and A2, the water temperature $\left(16^{\circ} \mathrm{C}\right)$ and the stocking density $\left(30 \mathrm{~kg} / \mathrm{m}^{3}\right)$ were kept constant at the optimal range throughout the 8-day experiment. The thermal-challenge sub-experiment (labelled in red here and in the following figures) was performed in the tanks $\mathrm{B} 1$ and $\mathrm{B} 2$, where the water temperature was gradually increased to $27^{\circ} \mathrm{C}$ while maintaining a stocking density of $30 \mathrm{~kg} / \mathrm{m}^{3}$. The combined-challenge sub-experiment (labelled in blue) in tanks $\mathrm{C} 1$ and $\mathrm{C} 2$ exposed rainbow trout to a high stocking density of $100 \mathrm{~kg} / \mathrm{m}^{3}$ while gradually increasing the water temperature to $27^{\circ} \mathrm{C}$. Blood samples, spleen and head kidney samples of seven trout from each tank were taken by the end of the experiment and used for the analysis as indicated below the scheme.

A

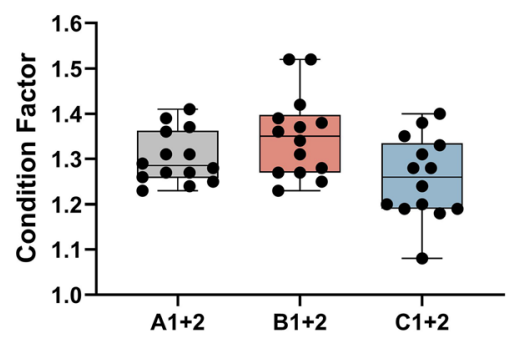

D

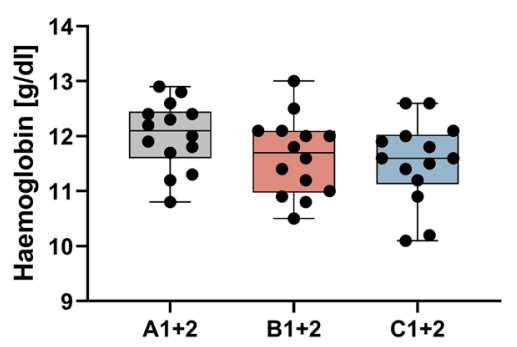

B

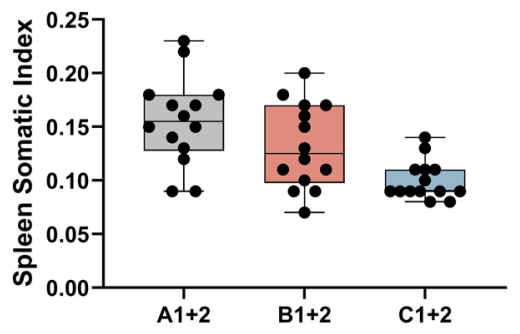

$\mathbf{E}$

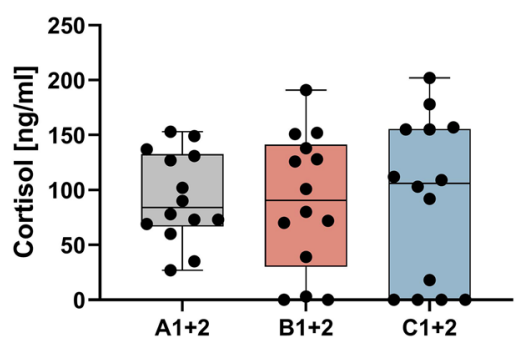

C

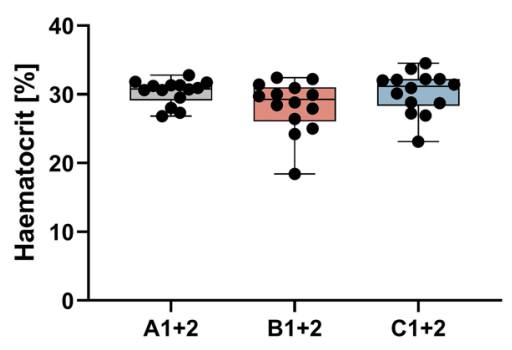

$\mathbf{F}$

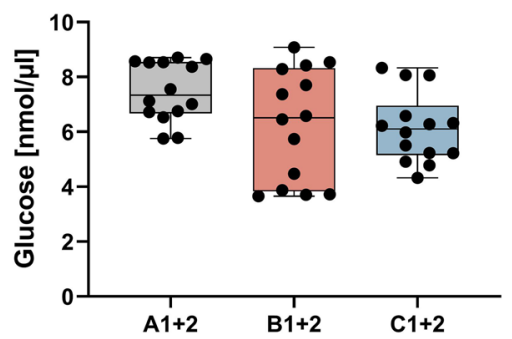

Figure 2. Condition indices and blood parameters. Box and whisker plots illustrating (A) condition factor, (B) spleen-somatic index, (C) haematocrit [\%], (D) haemoglobin [g/dl], (E) cortisol concentration [ng/ml] and (F) glucose concentrations $[\mathrm{nmol} / \mu \mathrm{l}]$ in plasma of 14 individuals from the experimental tanks as listed along the abscissa ( $c f$. Figure 1). Individual measuring points are indicated by black dots; error bars indicate standard deviation.

Gradual thermal rise to a temperature of $27^{\circ} \mathrm{C}$ (thermal-challenge group B) caused the different regulation of 831 features in the spleen-i.e., 521 upregulated and 310 downregulated features (Fig. 3A) -relative to the reference group A, which was kept at $16^{\circ} \mathrm{C}$. Accordingly, approximately two-thirds $(62.7 \%)$ of the entire set of differentially expressed (DE) genes in the spleen of rainbow trout exposed to high temperature was upregulated. These DE genes were assigned to 140 canonical pathways using the ingenuity pathway (IPA) programme. The 


\section{Thermal challenge}

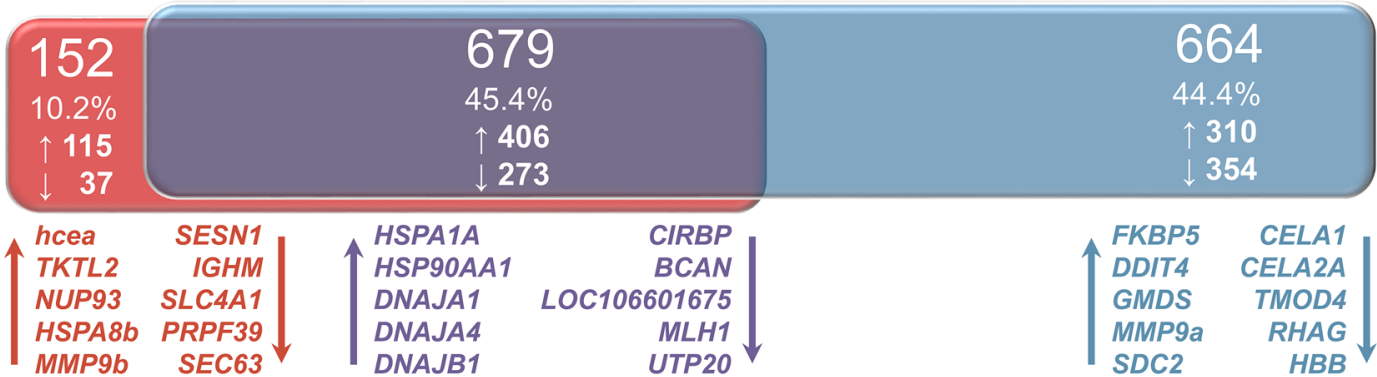

B

\section{Thermal challenge}

NRF2-mediated oxidative stress response

Unfolded protein response

Protein-ubiquitination pathway

Cholecystokinin/Gastrin-mediated signalling Aryl-hydrocarbon-receptor signalling

Production of nitric oxide and reactive oxygen species

Acute-phase-response signaling

eNOS signalling

CXCL8 signalling

IL12 signalling and production in macrophages

Primary immunodeficiency signalling

Th1- and Th2-activation pathway

Antigen-presentation pathway

IL7-signalling pathway

Tec-kinase signalling

Glycolysis/gluconeogenesis

Glutathione-redox reactions

Nucleotides degradation

Urate biosynthesis/Inosine 5'-phosphate degradation

Vitamin-C transport

z-scores
0.0

$-0.5$

\section{Combined challenge}

Unfolded protein response

NRF2-mediated oxidative stress response

Protein-ubiquitination pathway ERK/MAPK signalling

Glucocorticoid-receptor signalling

Production of nitric oxide and reactive oxygen species

IL12 signalling and production in macrophages

Macropinocytosis signalling

Iron-homeostasis signalling pathway

CXCL8 signalling

B-cell-receptor signalling

Th1- and Th2-activation pathway

IL7-signalling pathway

IL3 signalling

T-cell-receptor signalling

LXR/RXR activation

Glycolysis/gluconeogenesis

Glutathione-redox reactions

Heme biosynthesis

Vitamin-C transport
3.5

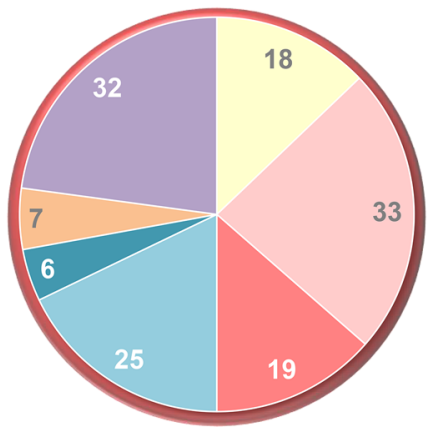

C1

Figure 3. Classification of differently expressed genes. (A) Venn diagram illustrating the absolute number, the percentage and the number of up- $(\uparrow)$ and down-regulated $(\downarrow)$ DE features in the spleen of rainbow trout exposed to high temperature (red), or high temperature combined with crowding (blue) relative to the expression values obtained for the reference group. The overlap (purple) depicts the proportion of DE genes shared by both challenge groups. The diagram was calculated based on Agilent ID lists; the five most up-and downregulated genes in the respective lists are shown below the Venn diagram. (B) A pathway analysis of those genes differentially expressed after thermal challenge (left side of table) and after combined challenge (right side). The pathways were sorted according to the biofunction categories "stress response", "innate immunity", "adaptive immunity" and "metabolic processes"; the 5 most strongly affected pathways are listed. The colour code below the table indicates the $\mathrm{z}$-score values. The total number of affected pathways was assigned to seven categories, which are shown in the two separate pie charts for $(\mathbf{C 1})$ temperature stress alone or $(\mathbf{C} 2)$ combined temperature/crowding stress. 
three most highly temperature-affected pathways were assigned to the biofunction category "stress response". These were (1) the nuclear factor erythroid 2-related factor (2NRF2)-mediated oxidative stress response (involving $27 \mathrm{DE}$ genes), (2) unfolded protein response (14 DE genes) and (3) protein ubiquitination pathway (23 DE genes) (Fig. 3B).

Almost a quarter of the temperature-affected pathways $(23.6 \% ; n=33)$ were attributed to the ,innate immune system “ (Fig. 3C1). A similarly high proportion was assigned to the category „metabolic processes “ $(22.9 \%$; $n=32)$, whereas the number of pathways associated with the „adaptive immune system “ $(13.6 \% ; n=19)$ and "stress response" (12.9\%; $n=18)$ was significantly lower.

Gene-expression profiling in the spleen of trout exposed to a high temperature combined with crowding. The combination of high temperature and crowding (combined-challenge group $\mathrm{C}$ ) resulted in $1,343 \mathrm{DE}$ genes in the spleen of challenged trout as compared to reference group A. In comparison with the expression data from the thermal-challenge group B versus group $\mathrm{A}$, the upregulated genes increased in the combined-challenge group C by $37.4 \%$ to $716 \mathrm{DE}$ genes, and the downregulated genes increased by $102.3 \%$ to $627 \mathrm{DE}$ genes. Consequently, the ratio of up- and downregulated features after the combined challengeaccounting for $56.6 \%$ and $43.4 \%$, respectively-revealed more balance than what was observed with high temperature alone.

The list of genes differentially expressed in response to the combined challenge was assigned to 213 canonical signalling pathways. As with the temperature-affected pathways, the NRF2-mediated oxidative stress response (involving $35 \mathrm{DE}$ genes) and the unfolded protein response (19 DE genes) were the two major pathways affected by the combined challenge. More than a quarter of the pathways affected by high temperature and crowding $(26.3 \%$, $n=56$ ) were attributed to the category "cell function, proliferation and differentiation" (Fig. 3C2). Approximately a fifth of all affected pathways were related to "innate immunity" (21.6\%, $n=46)$. In comparison, the combined challenge modulated a significantly lower number of pathways associated with the "adaptive immune system" $(13.1 \% ; n=28)$ and "stress response" $(11.7 \% ; n=25)$.

Identification of common and unique splenic pathways modulated by high temperature alone or by the combined temperature/crowding challenge. The two DE gene lists derived from the thermal-and combined-challenge sub-experiments share 679 common genes (Fig. $3 \mathrm{~A}$ ). Of these, the greater proportion of 406 genes $(59.8 \%)$ was upregulated. Noteworthy, $10.1 \%$ of these upregulated features $(n=41)$ belong to the family of heat-shock protein (HSP)-encoding genes. These include the HSP90/HSPC, HSP70/HSPA, HSP40/ DNAJ and HSP47/SERPINH1 members. These HSP-encoding genes were also the most strongly upregulated features, while cold-inducible mRNA binding protein $(C I R B P)$ was the most strongly downregulated gene $(<-14-$ fold) in both gene sets (Fig. 3A). Moreover, $6.2 \%$ of the downregulated genes $(n=17)$ were associated with the heavy or light chain of the different immunoglobulin types in trout.

Accordingly, the analysis of the pathways induced by the thermal challenge and the combined challenge revealed that the typical "stress pathways" that are dependent on HSPs (the unfolded protein response, the NRF2mediated oxidative stress response and the protein-ubiquitination pathway) and immunoglobulins (primary immunodeficiency signalling), were significantly affected by both experimental conditions (Fig. 3B). In addition to the biofunction cluster "stress response", the categories "innate immunity" (production of nitric oxide and reactive oxygen species, CXCL8 signalling, IL12-signalling and production in macrophages), "adaptive immunity" (Th1- and Th2-activation pathway, IL7-signalling pathway) and "metabolic processes" (glycolysis/gluconeogenesis, glutathione-redox reactions, vitamin-C transport) contain pathways which were highly affected both by high temperature alone and by the combined challenge (Fig. 3B). In essence, the high proportion of commonly regulated genes is well reflected by a high degree of shared pathways, which indicates the various physiological aspects of a response to adverse water temperatures (Fig. $3 \mathrm{C} 1$ ) and the combination of adverse temperatures and stocking densities (Fig. 3C2). Nevertheless, it should be noted that the number of pathways belonging to the category ,cell function, proliferation and differentiation " $h a s$ more than doubled in the combined-challenge dataset $(n=56$, Fig. 3C2) compared with the thermal-challenge dataset ( $n=25$, Fig. 3C1).

The comparison of both DE-gene lists also revealed clusters of DE genes which were uniquely regulated either after thermal or after combined challenge (Fig. 3A). Critical temperature alone regulated 152 unique features (i.e., those genes not included in the DE gene list of the combined-challenge group), 115 (75.7\%) of which were upregulated. In comparison, the combined challenge altered the expression of more than a fourfold number of unique genes $(n=664)$ with about a similar amount of up regulated features $(n=310)$ was there were downregulated features $(n=354)$.

The exclusive thermal-challenge DE genes were involved in 140 pathways, while the exclusive combinedchallenge DE genes were involved in 213 pathways (Fig. 4A). Both pathway sets overlapped by $52 \%$ with 120 shared pathways, majorly the unfolded protein response, the NRF2-mediated oxidative stress response or eNOS signalling (Fig. 4B, central pie chart). In the thermal-challenge group, only 20 pathways were uniquely modulated, including the activated melatonin-signalling pathway and four downregulated pathways (Fig. 4B, left pie chart). Remarkably, almost half of these temperature-affected pathways were related to metabolism $(n=9)$. In the combined-challenge group, 93 pathways were uniquely modulated, a third of which were predicted to be upregulated $(n=31)$ and a fifth of which was predicted to be downregulated $(n=19)$. Most of these combinedchallenge-affected pathways were related to cellular functions $(n=34)$ and innate immunity $(n=19)$. Compared to the thermal-challenge dataset, the proportion of metabolic pathways was significantly decreased (from 45 to $11 \%$ ) in the combined-challenge dataset, while the proportion of cellular functions increased (from 15 to $37 \%$ ). Moreover, DNA-replication and gene-expression pathways $(5 \%, n=5)$ were affected by the combined challenge, but not by high temperature alone. 


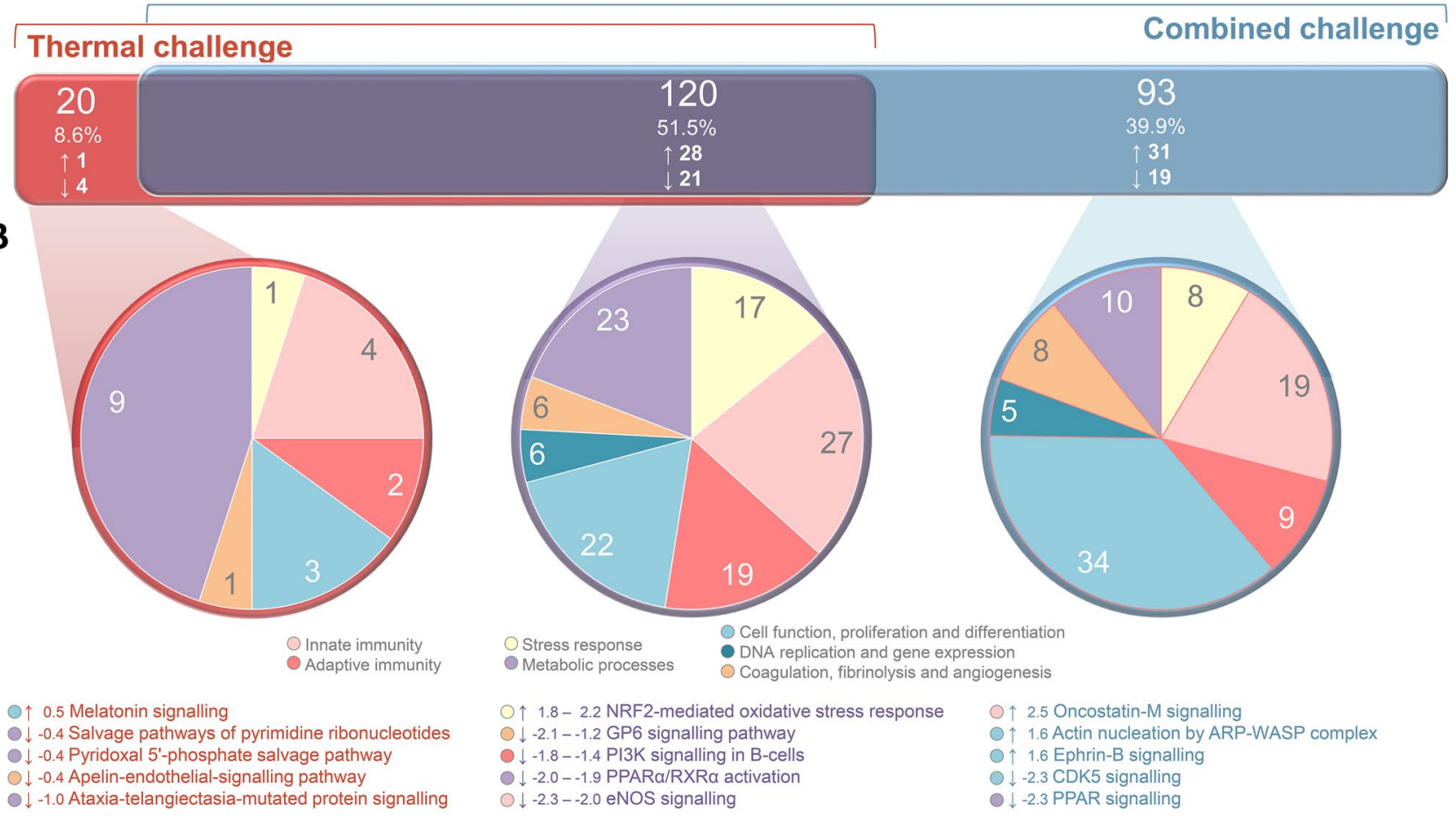

Figure 4. Classification of canonical pathways. (A) Venn diagrams illustrating the absolute number, the percentage and the number of activated $(\uparrow)$ and repressed $(\downarrow)$ pathways in the spleen of rainbow trout exposed to high temperature (red), or high temperature combined with crowding (blue) based on the $816 \mathrm{DE}$ genes which are unique for one of the challenges. The pathways were sorted according to the same seven biofunction categories introduced in Fig. 3C. The pie charts depict the categorised pathways (B1) exclusively affected by thermal challenge, (B2) commonly affected by thermal and combined challenge and (B3) exclusively affected by combined challenge. The five most strongly affected pathways are listed with their $\mathrm{Z}$-score values below the charts.

Impact of combined challenge on the growth of bacteria in trout serum. A common test for assessing immune capacity is to record the growth of bacteria in blood plasma ${ }^{49,50}$. In the plasma of rainbow trout exposed to high water temperature (group B) or high temperature combined with crowding (group C), we counted 7.8 to 27.5 times more A. salmonicida after 24 -h incubation compared to the bacterial growth in the plasma of reference trout (group A) (Fig. 5).

Impact of combined challenge on the composition of peripheral blood leukocytes. Since leukocyte profiles are considered informative stress indicators ${ }^{51}$, we analysed the cell composition of peripheral blood leukocytes in the combined-challenge group (group C) relative to the reference fish (group A). To evaluate the proportion of thrombocytes, IgM-positive B cells, T cells and myeloid cells, we used a previously established flow-cytometry protocol ${ }^{52}$. While the proportion of myeloid cells remained at a similar level (Fig. 6A), the proportion of IgM-positive B cells decreased from $41.8 \%$ in the control group to only $2.4 \%$ in the combinedchallenge group (Fig. 6B). Similarly, the proportion of T cells dropped from $4.4 \%$ (group A) to $1.0 \%$ (group C) (Fig. 6C), simultaneously with the proportion of thrombocytes decreasing from $25.1 \%$ (group A) to $15.4 \%$ (group C) (Fig. 6D).

Expression profiling of immune-relevant genes in stimulated head-kidney cells from challenged versus non-challenged trout. Finally, we determined the impact of previous exposure to critical temperature and crowding on immune responses in vitro. To this end, we isolated head-kidney cells from trout of groups A (reference) and C (combined challenge), stimulated these leucocyte-enriched cultures with $A$. salmonicida and profiled the expression of the inflammation-related genes TNF, IL1B, CXCL8, IL6, TGFB1 and MHCIIB.

In the head-kidney cells of control group A, the expression of the immune marker genes TNF, IL1B, CXCL8 and IL6 (Fig. 7A-D) increased significantly in response to live A. salmonicida while the expression of TGFB1 and $M C H C I I B$ slightly decreased (Fig. 7E,F). A transcriptional response to the stimulation with inactivated $A$. salmonicida was also detectable but less pronounced. The stimulation of head-kidney cells from group $\mathrm{C}$ with inactivated $A$. salmonicida did not modulate the transcript levels of the investigated cytokines (Fig. 7, blue bars). In contrast, the stimulation with A. salmonicida increased the expression of IL1B, CXCL8 and IL6, although to a lower extent as observed for control group A. 


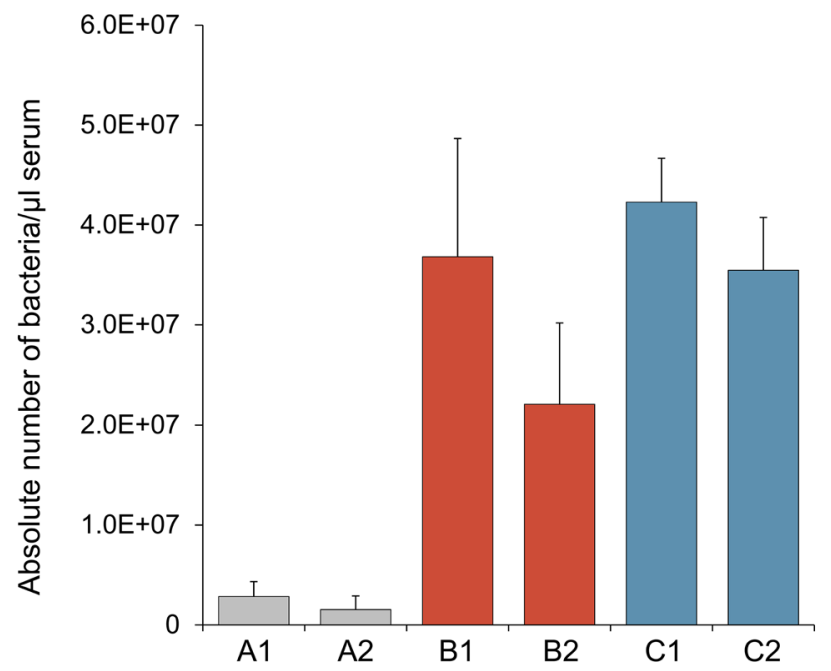

Figure 5. Quantification of the A. salmonicida titre in serum isolated from rainbow trout from the experimental tanks as listed along the abscissa ( $c f$. Figure 1). Graphs represent the mean values of five fish $+\mathrm{SD}$ (error bars).
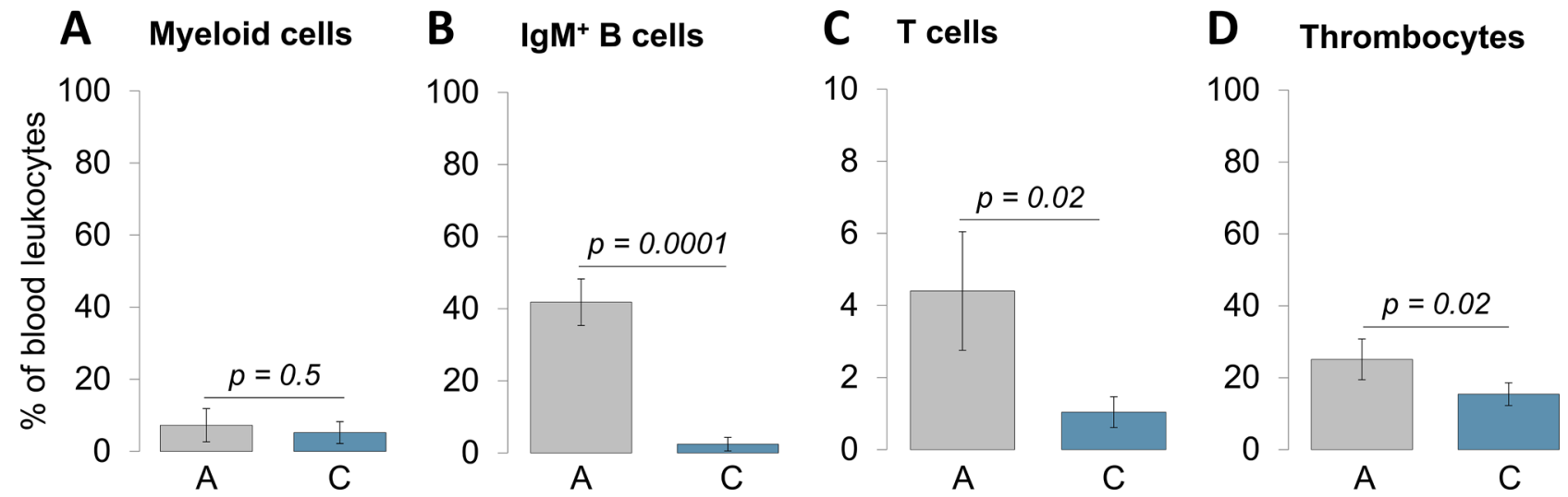

Figure 6. Quantification of the proportion of $(\mathbf{A})$ myeloid cells, $(\mathbf{B})$ IgM-positive B cells, $(\mathbf{C}) \mathrm{T}$ cells and (D) thrombocytes relative to the total amount of blood leukocytes. The cell-sorting procedures were performed with leukocytes from non-challenged rainbow trout (grey bars) and rainbow trout exposed to the combined challenge (blue bars). Graphs represent the mean values of 10 fish (five fish per tank) \pm SD (error bars). $P$ values are indicated.

\section{Discussion}

The persistent challenge of rainbow trout in the present study is reflected by distinct expression profiles, but not by altered condition indices and blood parameter levels. The rapid and reliable detection of an informative set of (salmonid-specific) bioindicators allows conclusions on the nature and severity of a multifactorial stress burden and thus significantly improve animal-welfare concepts and the health of farmed fish in aquaculture facilities. The objective of the present study was to discover novel animal-based biomarkers and evaluate well-known existing ones based on transcriptome profiling and to derive inferences about the onset of suggestive pathways. The combination of different techniques, which allow quantifying multiple parameters with relevance to distinct stress responses, is established as a promising approach to assess the individual welfare status ${ }^{53}$.

The present study was based on the recording of primary (cortisol level), secondary (glucose level, haematocrit, leukocyte count, gene expression) and tertiary (condition factor, spleen-somatic index, cellular immune competence) stress indicators. Notwithstanding our expectations, the levels of the analysed non-transcript-based parameters were non-significantly different between the reference $(A)$ and challenge groups $(B, C)$, which might indicate similar physiological states of the animals investigated. The body-score values, in particular, were in the physiological range ${ }^{5-56}$. In stark contrast, the microarray analysis and subsequent experiments with primary cell cultures from control and challenged fish indicate extensive physiological reactions following the experimental challenge. This apparent contradiction is likely to have arisen from the sampling time point chosen. The duration 
A

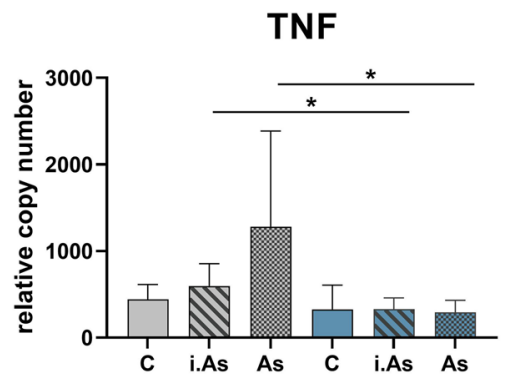

D

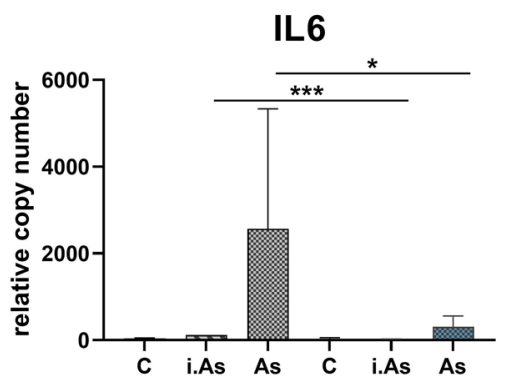

B

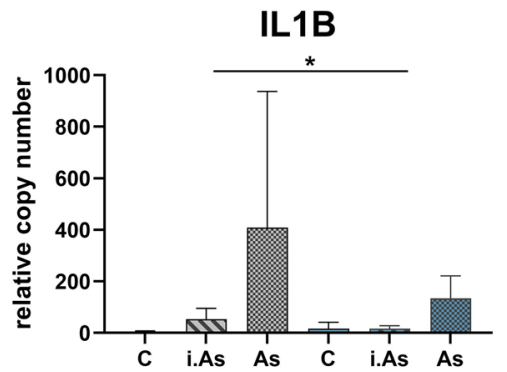

E

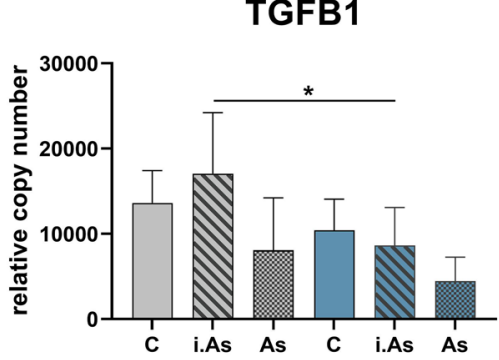

CXCL8

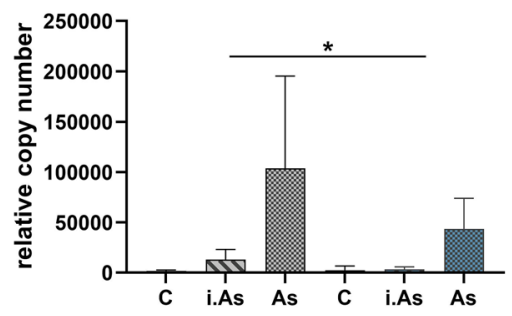

$\mathbf{F}$

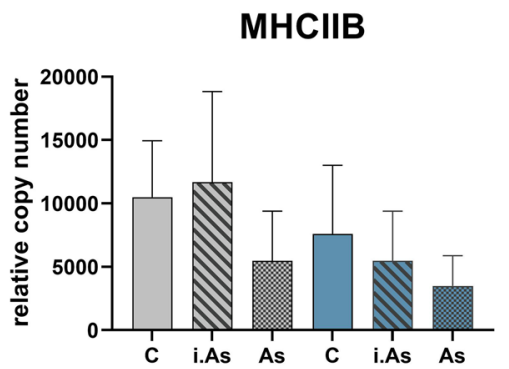

Figure 7. Expression profiling of (A) TNF, (B) IL1B, (C) CXCL8, (D) IL6, (E) TGFB1, and (F) MHCIIB in stimulated head-kidney cells isolated from five non-challenged fish (grey bars) or fish exposed to combined challenge (blue bars). Bars represent the mean copy number $+\mathrm{SD}(n=8$; four fish per tank) normalised to the reference gene EEF1A1. Cells from both challenge groups remained untreated (non-textured bars) or they were stimulated with inactivated (i.As; hatched bars) or viable A. salmonicida (As; spotted bars). Significant differences in expression relative to the transcript level in the control group are indicated by asterisks $\left({ }^{\star}, p<.05 ;{ }^{* *}, p<.001\right)$.

of our experiment ranged between "short-term" and "long-term" and might correspond to a state well after the acute response to the disturbed homeostasis but presumably before the desensitisation to (a) stressor(s) associated with the adaptation processes. The plasma cortisol level, for instance, is undoubtedly an informative indicator of acute stress but in rare cases for chronic stress ${ }^{57}$. The same applies to the glucose concentration ${ }^{58}$. The blood glucose concentrations of all animals examined here were slightly above normal ${ }^{59}$ and most likely reflect our adlibitum feeding regime. Whereas glucose levels should therefore not be overestimated as an indicator of stress in the present study, the measured cortisol concentrations indicate a general activation of the hypothalamus-pituitary-interrenal axis, commonly known as the stress axis. Although strikingly different cortisol levels have been reported in Oncorhynchus spp. under pre-stress conditions $(<2->500 \mathrm{ng} / \mathrm{ml})^{5}$, a concentration below $10 \mathrm{ng} / \mathrm{ml}$ is generally considered physiological ${ }^{60}$, and a concentration above $40 \mathrm{ng} / \mathrm{ml}$ indicates stress ${ }^{58,60}$. In the present study, the elevated cortisol concentrations likely do not mirror the exposure to adverse temperature and stocking density but rather the acute stress of the sampling procedure including netting, transfer and anaesthesia ${ }^{61-63}$, accompanied by significant inter-individual variabilities. However, the transcription of genes involved in acute stress responses takes a significantly longer period of time ${ }^{64}$ than is required to catch and anaesthetise fish. For this reason, the quantification of transcript levels is supposed to be the more suitable technique in the present study to assess the long-term responses to adverse environmental conditions. If another, uncontrolled factor elevated the cortisol concentration in control and challenged trout, we cannot exclude that this unknown factor also influenced the expression profiles of the three treatment groups and weakened the expression differences.

Regarding the critical temperature of $27^{\circ} \mathrm{C}$ and the no less-critical stocking density of $100 \mathrm{~kg} / \mathrm{m}^{3}$, it would be expected that several functional pathways are induced, which are related to the heat shock, increased energy demand and altered immune defence. The questions remain (1) whether the clear transcriptional responses observed on day eight after the onset of the heat challenge and the heat-crowding challenge, respectively, attenuate or augment over a further extended challenge period and (2) to what extent the presently recorded transcript levels are representative for the long-term exposition to these challenge factors. We can only speculate that the persistent challenge with such an extreme water temperature and the inconvenient stocking conditions will increasingly display various tertiary indicators on the whole-body performance, which would indicate serious detrimental effects and elevated mortality of the rainbow trout.

Critical temperature and crowding interact synergistically. Our transcriptomic analyses of the rainbow trout spleen revealed that the combination of high temperature $\left(27^{\circ} \mathrm{C}\right)$ and high stocking density $\left(100 \mathrm{~kg} / \mathrm{m}^{3}\right)$ results in an increased number of DE genes by $162 \%$ compared with high temperature $\left(27^{\circ} \mathrm{C}\right)$ alone. Of these, the proportion of upregulated genes was 1.3- to 1.7-fold greater than the proportion of downregulated 
genes. It is hardly surprising that almost half of the overall regulated genes were present in both sets, as the two challenge groups have been exposed to high temperatures, which are known as major stressors for poikilothermic fish. Nevertheless, we identified two sets of uniquely regulated genes that characterise the response to either high temperature alone or high temperature combined with crowding. Remarkably, the number of DE genes unique to the combined challenge is more than four times higher than the number of DE genes unique to the thermal challenge. This suggests a synergistic interaction of the two challenge factors, especially since our previous study on stocking density in rainbow trout ${ }^{36}$ under similar experimental conditions provided only between one (kidney) and a maximum of 249 (liver) regulated genes, depending on the analysed tissue. The synergistic effect of high temperature and overstocking on the rainbow trout's physiology is well in line with a meta-analysis by Crain and colleagues, who concluded from 171 studies that multiple stressors generally interact synergistically in marine systems ${ }^{3}$. In this context, the question arises as to which threshold value the stressors must exceed to produce synergistic effects and-in the present case-if the combination of a lower water temperature and/or lower stocking density would have generated additive instead of synergistic effects.

The signature of thermal stress is conserved across teleost fishes. A considerable number of studies have already profiled the transcriptional changes of different organs of salmonids leaving their thermopreferendum ${ }^{23,24,27,28,30,65-69}$. We ${ }^{69}$ and others ${ }^{24}$ have recently reviewed our own and external transcriptome studies to identify biomarkers of salmonid fish, which indicate a stress response to inconvenient temperatures. Both studies agree that mainly SERPINH1/HSP47, HSPA1A/HSP70 and HSP90AA1/HSP90 have enormous potential as "robust thermally-responsive biomarkers" following many other reports on these three heat-shock proteins ${ }^{23,25,27-30,65-68,70-74}$. In contrast to the regulation of HSPs, CIRBP is strongly downregulated in salmonid fish upon heat stress ${ }^{23,24,27,69}$, while members of the FK506-binding protein family show distinct expression profiles with FKBP5 being upregulated and FKBP10 being downregulated ${ }^{24,69}$. Five of these six biomarker genes (SERPINH1, HSPA1A, HSP90AA1, CIRBP, FKBP10) were significantly regulated by both the thermal challenge and the combined challenge, while FKBP5 emerged exclusively after combined challenge.

Based on the published DE gene sets responding to heat stress in salmonids, numerous indicative functional pathways were identified. Interestingly, we found that the NRF2-mediated oxidative stress response and the unfolded protein response were the dominant pathways to responding to critical temperature. The combined challenge in the present study and both pathways were also highly affected after gradual and acute heat stress in different tissues of maraena whitefish ${ }^{69}$. Only 20 pathways were uniquely regulated in response to a high temperature, i.e., they are not present in the list of genes that were differentially regulated in response to the combined challenge. Of these, only melatonin signalling was predicted to be positively regulated. This pathway has been described to improve the oxidative status of fish cells, for instance after the activation of reactive oxygen species ${ }^{75}$.

The signature of crowding is subtly contained in the identified gene lists and pathways upregulated upon combined challenge. Far less is known about those genes characteristically regulated by overstocking in (salmonid) fish. Remarkably, comparative analyses showed that rainbow trout, which have been domesticated for decades in intensive aquaculture, respond considerably less sensitively to crowding than the salmonid maraena whitefish (Coregonus maraena), which was only recently introduced in aquaculture ${ }^{9,36}$. Hypoxia-inducible factor 1-alpha (HIF1 $\alpha$ ) signalling was the only pathway found to be activated in the liver of rainbow trout exposed to a high stocking density of $120 \mathrm{~kg} / \mathrm{m}^{3,36}$. After the combined challenge in the current study, we also identified this pathway regulated in the spleen. Two other pathways, the protein ubiquitination pathway and PI $3 K / A K T$ signalling, were repressed in the liver of rainbow trout exposed to a high stocking density $^{36}$. It is worth noting that in the present study, we found these pathways with an undefined or slightly positive $\mathrm{z}$-score (which corresponds to a slight activation) in trout challenged with a high temperature and crowding. In the combined challenge, 93 pathways were uniquely regulated. Of these, significantly more pathways were activated than suppressed, and a third of these genes are associated with innate immunity (oncostatin-M signalling, NF- $\kappa B$ signalling, STAT3 pathway, toll-like receptor signalling) or adaptive immunity (Fc $\gamma$ RIIB signalling in $B$ cells, NUR77 signalling in T cells).

Critical temperature combined with crowding impacts a number of immunological pathways and translates to substantial changes in the immune capacity of rainbow trout. Various stressors have been reported to threaten the health of farmed fish in aquaculture. For this reason, it is particularly interesting to investigate the crosstalk between the immune system and stress responses in farmed fish. In our previous study on maraena whitefish, we demonstrated that a high stocking density of $100 \mathrm{~kg} / \mathrm{m}^{3}$ increased a considerable number of immune-relevant genes ${ }^{9}$. A quarter of all upregulated genes in the liver and a fifth of all upregulated genes in the kidney of challenged maraena whitefish were related to immunological processes including complement cascade, acute-phase response signalling, chemokine signalling, B-cell-receptor signalling and leukocyte-extravasation signalling. This set of immune pathways is intriguingly similar to the set of induced immune pathways in the liver of large yellow croaker (Larimichthys crocea) exposed high stockingdensity conditions ${ }^{76}$. The respective pathways belong to the innate immune system (complement and coagulation cascades, toll-like receptor signalling and chemokine signalling) and the adaptive immunity ( $T$-cell, B-cell receptor signalling and leukocyte-migration pathway).

In our current study, we also observed notable changes in the expression of genes involved in various innate and adaptive immune pathways. However, the transcriptional changes caused by the gradual increase of the water temperature mainly activated innate-immune mechanisms such as CXCL8 signalling and production of nitric oxide and reactive oxygen species, apparently to bring the organism into a "watch out" position in anticipation of an increased pathogen pressure. Notwithstanding, we found a decreased bactericidal activity in the plasma 
of challenged trout compared with non-challenged trout. The complement system is an important immune complex tasked with the elimination of bacteria ${ }^{77,78}$, and we can only assume that several transcripts encoding complement components were downregulated in the liver (the main site of complement synthesis but not considered in this study).

The analysis of the splenic transcriptome clearly revealed that the exposure to combined challenge modulates both arms of the immunity. High water temperature combined with crowding induced several pathways of the innate immunity (CXCL8 signalling, production of nitric oxide and reactive oxygen species and micropinocytosis signalling), while several pathways of the adaptive immunity were downregulated. Of particular importance is not only the decreased expression of genes involved in the B-cell-receptor signalling, but also the negative regulation of the IL7-signalling pathway, which contributes to early T-cell development and to mature T-cell maintenance. This was confirmed by the altered composition of peripheral blood leukocytes, chiefly by a reduction of B cells, $\mathrm{T}$ cells and thrombocytes in fish exposed to combined challenge compared to non-challenged fish. This is well in line with a large number of studies that identified a common pattern of lymphopenia and neutrophilia in the circulation of various fish species exposed to different types of stress ${ }^{9,79,80}$. Overall, the number of phenotypically identifiable cells from challenged rainbow trout was reduced from about $80 \%$ to $25 \%$ but unfortunately, the available tools did not allow additional information on the nature of the remaining $75 \%$ peripheral blood leukocytes from challenged fish to be obtained.

Previously, we had shown with maraena whitefish that adverse environmental conditions do not only influence the transcriptomic programmes in lymphoid organs and the composition of circulating leukocytes but also negatively impact the organism's ability to react towards pathogens ${ }^{9}$. Using this established protocol, we demonstrate here that the primary culture of head-kidney cells from rainbow trout exposed to the combined challenge showed a dramatically reduced ability to induce the expression of IL1B,CXCL8, TNF and IL6 upon stimulation with both viable and inactivated A. salmonicida. The extent of this downregulation becomes even more evident in comparison to the less pronounced changes induced by crowding alone in maraena whitefish. Taken together, our immunologic analyses confirm the conclusions drawn from our transcriptomic data, which suggest that critical temperature and crowding together have a synergistic effect, especially on the immune capacity of challenged fish. Although rainbow trout were not exposed to pathogens in the present experiment, we assume that an increase in opportunistic pathogens would lead to severe infections and increased death rates of acutely stressed trout. This hypothesis should be verified in future experiments.

\section{Conclusions}

It has been established that temperature and crowding stress have different molecular signatures, which reflect different mechanisms of adaptation. So far, very few data sets have been interpreted concerning the question of how different adaptation mechanisms to simultaneous stressors influence each other. The present study demonstrates that critical temperature combined with crowding activates synergistically a cluster of compensatory responses including cell-signalling, immune and metabolic pathways. Besides, we document that a high temperature combined with overstocking impair the bactericidal and inflammatory activity, significantly alter the blood-cell composition and exert thus a profound impact on the fish's immune system. Stress does not only compromise the health and general well-being of fish but also reduces the profits of a fish farm.

Our study suggests, once again, to carefully select the parameters for monitoring the response of the fish to one or multiple potential stressors, which are effective over longer periods. High-throughput methods such as RNA-sequencing or microarray analysis allow stress-specific signatures of certain tissues and even cells to be recorded. Although the transcriptome analyses might add valuable information into the physiological events involved in restoring homeostasis, these methods are usually cost-intensive. This study suggests some transcriptomics-based rainbow trout-specific biomarkers that may be relevant for indicating compromised well-being, although they need to be evaluated in an aquaculture practice. Robust parameters resulting from this evaluation can be quantified in a range of specimens through simple and cost-effective methods such as quantitative realtime PCR and extend the available spectrum of welfare biomarkers.

\section{Materials and methods}

Experimental design and sampling. Rainbow trout at the age of $\sim 10$ months were randomly distributed over six experimental 309-1 tanks integrated into a RAS. The experimental procedures are illustrated in Fig. 1. The stocking density in four of the six experimental tanks (A1, A2, B1, B2) has been set to $30 \mathrm{~kg} / \mathrm{m}^{3}$ (corresponding to 38 or 39 trout each weighing $9.5 \mathrm{~kg}$ ), while the stocking density in the other two tanks $(\mathrm{C} 1, \mathrm{C} 2)$ was $100 \mathrm{~kg} / \mathrm{m}^{3}$ (corresponding to 96 or 119 trout weighing $35 \mathrm{~kg}$ ). Two of the tanks with $30 \mathrm{~kg}$ of trout per cubic metre (A1, A2) served as control tanks and were kept at a constant temperature of $16^{\circ} \mathrm{C}$ for the duration of the experiment (Fig. 1, reference). The water temperature in the other tanks (B1, B2, C1, C2) was elevated by $2^{\circ} \mathrm{C}$ every day for 5 days, gradually going from 16 to $26^{\circ} \mathrm{C}$. On day six, the temperature was increased by $1{ }^{\circ} \mathrm{C}$, and on day seven, the tanks were kept at $27^{\circ} \mathrm{C}$ for $24 \mathrm{~h}$. The water temperature and other relevant parameters including $\mathrm{NH}_{4}{ }^{+}, \mathrm{NO}_{2}{ }^{-}, \mathrm{NO}_{3}^{-}$(in each case far below critical values), $\mathrm{pH}$ (between 7.3 and 8.5) and dissolved $\mathrm{O}_{2}$ were constantly recorded. Trout were fed ad libitum commercial dry pellets by automatic feeders. Throughout the experiment, no technical problems were registered. Further husbandry conditions are detailed in reference ${ }^{36}$. Eight days after the start of the experiment, seven rainbow trout per tank (A1, A2, B1, B2, C1, C2) were randomly sampled using hand nets. The fish were quickly transferred to a bucket of water and sedated using an overdose of phenoxyethanol. The handling of fish before blood and tissue sampling was conducted in compliance with the terms of directive 2010/63/EU on the protection of animals used for scientific purposes. The experimental protocol was approved by the Ministry of Education, Youth and Sports, Prague, Czech Republic (approval ID: MSMT-18301/2018-2). 
The rainbow trout had reached an average length of $26.2 \pm 1.3 \mathrm{~cm}$ (mean \pm standard deviation, STD) and an average weight of $230.2 \pm 35.9 \mathrm{~g}$ at the end of the experiment. Blood was taken from the caudal vein of every trout killed using $1-\mathrm{ml}$ plastic syringes filled with $500 \mu \mathrm{l} 0.5 \mathrm{M}$ ethylenediaminetetraacetic acid (EDTA, pH 8.0) solution as anticoagulant. The spleens of the fish were isolated, snap-frozen in liquid nitrogen and stored at $-80^{\circ} \mathrm{C}$ until nucleic acid extraction. Head-kidney tissue was homogenised, passed through a 100 - $\mu \mathrm{m}$ strainer and washed with cold Dulbecco's Modified Eagle's Medium (DMEM, Thermo Fisher Scientific). The resulting cell suspension was loaded on a Percoll gradient (density $1.08 \mathrm{~g} / \mathrm{ml}$ ) and centrifuged for $20 \mathrm{~min}$ at $800 \times \mathrm{g}$. Following centrifugation, cells at the interphase were collected, washed twice in DMEM and resuspended to a final concentration of $5 \times 10^{6}$ cells $/ \mathrm{ml}$.

Blood-parameter analyses. Caudal blood samples from 42 fish were thoroughly mixed with ethylenediaminetetraacetic acid (EDTA) and processed in the haematological counter ABX Pentra 60 (HoribaABX Diagnostics) within $3 \mathrm{~h}$ after collection to determine the individual haematocrit and haemoglobin levels.

The residual blood samples were centrifuged $\left(4^{\circ} \mathrm{C}, 1,700 \times \mathrm{g}\right)$, and the supernatant was kept on ice until analysis of blood plasma parameters. Cortisol concentrations were determined using a Cortisol ELISA assay (DRG Instruments $\mathrm{GmbH}$ ) and plasma-glucose concentrations were measured using a colorimetric assay (Glucose Assay Kit II; BioVision). Both analyses were performed according to the manufacturer's instructions using a Beckman Coulter DTX 800/880 Series Multimode Detector (Beckman Coulter), which measured the absorbance at $450 \mathrm{~nm}$.

Bacteria growth serum. For the bacterial growth assay, the individual blood samples of trout were incubated in reaction tubes for up to $1 \mathrm{~h}$. After centrifugation $(1,700 \times \mathrm{g}, 10 \mathrm{~min}), 100 \mu \mathrm{l}$ of serum from each fish was inoculated with $2 \times 10^{5}$ bacteria Aeromonas salmonicida ssp. salmonicida wild-type strain JF2267. Sera with bacteria were incubated $24 \mathrm{~h}$ at $18{ }^{\circ} \mathrm{C}$. After incubation, the bacteria culture from each well was transferred to $1.5-\mathrm{ml}$ tubes and centrifuged at 7,500 $\mathrm{rpm}$ for $10 \mathrm{~min}$. The supernatant was discarded, and the total DNA was isolated from a pellet using a QIAamp DNA Blood Mini Kit (Qiagen) according to the manufacturer's protocol.

Flow cytometry. The composition of peripheral blood leukocytes was analysed using the protocol established previously ${ }^{52}$. Briefly, $2 \mu \mathrm{l}$ of heparinised blood was stained with the set of monoclonal antibodies (MAb) recognising thrombocytes (MAb 42-APC-Cy7) ${ }^{81}$, myeloid cells (MAb 21-RPE) ${ }^{52}$, IgM-heavy chain (MAb 1.14PerCp) and T cells (MAb D30-FITC). The samples were measured on FACS Canto II and analysed by DIVA software (BD Biosciences).

In vitro stimulation experiment. To investigate the effect of the combined challenge on the immune capacity of rainbow trout, a stimulation experiment with A. salmonicida (JF 2267) was performed. The bacteria were kept viable or inactivated in $1.5 \%$ paraformaldehyde (PFA) for $1 \mathrm{~h}$ and diluted to a final concentration of $5 \times 10^{7}$ cells $/ \mathrm{ml}$ in sterile phosphate-buffered saline (PBS). Isolated head-kidney cells of eight fish from the reference group A and the combined-challenge group $\mathrm{C}$ each were stimulated with $100 \mu \mathrm{PBS}, 1 \times 10^{6}$ viable or PFA-inactivated bacterium. After $12 \mathrm{~h}$ incubation $\left(\mathrm{CO}_{2}, 15^{\circ} \mathrm{C}\right)$, stimulated samples were collected and stored in $700 \mu \mathrm{l}$ RLT buffer until RNA preparation.

RNA preparation. TRIzol reagent (Invitrogen) in combination with the RNeasy Mini Kit (Qiagen) and the RNase-free DNase Set (Qiagen) was used to extract high-quality RNA from the above-listed tissues. The concentration and purity of the RNA was determined using the NanoDrop 1000 Spectrophotometer (NanoDrop Technologies/Thermo Fisher Scientific); RNA integrity was evaluated using the Agilent 2100 Bioanalyzer (Agilent Technologies) revealing values for RNA integrity ranging from 8.9 to 10 .

Array hybridisation. For microarray-based gene-expression analysis, we pooled equal shares of seven individual RNA samples isolated from the spleen in six separate specimens according to treatment and tank (A1, B1, C1; A2, B2, C2). These six RNA pools were converted to Cy3-labelled cRNA and hybridised with $8 \times 60 \mathrm{~K}$ Agilent-049158 Salmon Oligo Microarrays (Agilent Technologies; GEO platform: GPL21057) following the Agilent 60-mer oligo microarray processing protocol, as described in our previous paper $^{36}$. The fluorescence signals of the hybridised Agilent microarrays were scanned with a G2505C Microarray Scanner System (Agilent Technologies) at a resolution of $3 \mu \mathrm{m}$.

For all hybridisations, two technical replicates were included representing exactly the same samples but applied to independent arrays. The reliability of the microarray-predicted data has previously been proven in various quantitative PCR studies of our group ${ }^{9,23,69,82,83}$.

Quantitative real-time PCR analysis. Quantitative real-time PCR was performed using the LightCycler96 Real-Time PCR System (Roche) and SensiFAST SYBR No-ROX One-Step Kit (Bioline). RNA samples from the in vitro-stimulation experiment were reverse-transcribed using the Super Script II kit (Thermo Fisher Scientific) and a cDNA equivalent of $75 \mathrm{ng}$ total RNA was analysed for copy-number analysis. Gene-specific primers for the immune-related genes CXCL8,IL1B,TGFB1,TNF ${ }^{84}, I L 6^{85}$, and MHCIIB (sense, 5'-AGTACA CACCCAAGTCTGGAGA-3'; anti-sense, 5'-AGTCCTGCTAATGCTAAGATGGT-3') were used.

The number of bacteria was quantified on the CFX96 Touch Detection System (Bio-Rad) using SensiFAST SYBR one-step kit (Bioline) according to the protocol. As target gene, DNA gyrase (subunit B) was used (NCBI 
gene ID: 4994747; sense, 5'-TCATCATGACTGTGCTGCAC-3'; antisense, 5'-ATGGTCAGCAACAGCTTG $\left.\mathrm{T}-3^{\prime}\right)^{86}$.

Cycling conditions were as follows: $10 \mathrm{~min}$ pre-incubation; $15 \mathrm{~s}$ denaturation at $95^{\circ} \mathrm{C}, 10 \mathrm{~s}$ annealing decreasing from $60{ }^{\circ} \mathrm{C}, 20 \mathrm{~s}$ elongation at $72{ }^{\circ} \mathrm{C}$, and $5 \mathrm{~s}$ quantification at $75^{\circ} \mathrm{C}$. To assess the quality of individual PCR products, a melting-curve analysis was performed.

Data analyses. Statistical analyses of body-score indices (condition factor, spleen-somatic index, haematocrit) and plasma parameters were performed in GraphPad Prism 8.4.2 (GraphPad Software, Inc., San Diego, CA) with a significance level of 0.05 . Because all data were normally distributed (Kolmogorov-Smirnov, $p>0.05$ ), parametric $t$ tests were used.

The Agilent Feature Extraction Software (FES) 10.7.3.1 was used to read and process the microarray-image files with standard settings. The FES corrected the background using a two-sided Student $t$ test. The features that passed this quality control were further analysed with the limma package of the R-Version 3.1.1/Bioconductor-Suite ${ }^{87}$ ). Our customised scripts are available on request. Following quantile normalisation, pairwise comparisons between the treatments (reference vs. thermal challenge or combined thermal/crowding challenge) were employed to compare transcript abundances under the different treatment conditions. To control the false discovery rate, $p$ values were adjusted ${ }^{88}$. Only genes with a corrected $p$ value $(q$-value) of $<0.05$, and an absolute fold change of $>2.0$ were considered DE genes and included in further data processing.

Comparisons of gene expression across the different treatment conditions were performed using Venn Diagrams ${ }^{89}$. DE genes were re-annotated using the basic local alignment search tool (BLAST). We considered only transcripts with unique BLAST results (coverage and sequence identity of $>85 \%$ and E-value $<1 \times 10^{-4}$ ). Only $2.5 \%$ of all DE genes could not be annotated. A functional analysis was performed using the Ingenuity programme (Ingenuity Pathway Analyses/Qiagen) to evaluate global functional networks and canonical pathways of interacting genes and other functional groups.

Benjamini-Hochberg multiple testing was performed and $p$ values $>0.05$ were considered as a cut-off score. The output lists were carefully reviewed, and all those pathways and functions were deleted which were either associated with a mammalian disease or occurred in a tissue other than analysed. All relevant pathways are indicated in the following sections by italic face. Additionally, we assigned the canonical pathways to the biofunctions "stress response", "innate immunity", "adaptive immunity", "cell function, proliferation and differentiation", "DNA replication and gene expression", "coagulation, fibrinolysis and angiogenesis" and "metabolic processes". If certain pathways were assigned to more than one biofunction, we still only assigned them to one main category. The $z$-scoring system was used to evaluate whether a particular pathway was activated $(z>1)$ or repressed $(z<1)$.

The number of transcripts determined via quantitative PCR was calculated based on transcript-specific standard curves. To this end, the $\mathrm{C}_{\mathrm{q}}$ values of PCR products, having been amplified by the aforementioned primer pairs, were determined in serial tenfold dilutions starting from $1 \times 10^{2}$ to $1 \times 10^{8}$ copies. Based on these $\mathrm{C}_{\mathrm{q}}$ values, a calibration line was created, which allowed for the calculation of the copy numbers according to the formula copy number $=10^{\text {(Cq value-intercept)/(slope) }}$. The obtained values were normalised to the reference gene encoding the translation elongation factor EEF1 $\mathrm{Al}^{90}$.

In an analogous manner, the number of $A$. salmonicida in the serum of rainbow trout was determined. The number of cells per $\mathrm{ml}$ was calculated based on a calibration line. This has been generated based on the Cq values of the $g y r B$ transcripts determined for $1 \times 10^{4}-1 \times 10^{9}$ colonies.

\section{Data availability}

The full complement of microarray data generated and analysed during the current study was deposited in the NCBI GEO, https://www.ncbi.nlm.nih.gov/geo/; accession: GSE129271).

Received: 20 November 2019; Accepted: 24 August 2020

Published online: 10 September 2020

\section{References}

1. Sarà, G., Mangano, M. C., Johnson, M. \& Mazzola, A. Integrating multiple stressors in aquaculture to build the blue growth in a changing sea. Hydrobiologia 809, 5-17 (2018).

2. Pickering, A. D. Rainbow trout husbandry: management of the stress response. Aquaculture 100, 125-139 (1992).

3. Crain, C. M., Kroeker, K. \& Halpern, B. S. Interactive and cumulative effects of multiple human stressors in marine systems. Ecol. Lett. 11, 1304-1315 (2008).

4. Schulte, P. M. What is environmental stress? Insights from fish living in a variable environment. J. Exp. Biol. 217, 23-34 (2013).

5. Barton, B. A. \& Iwama, G. K. Physiological changes in fish from stress in aquaculture with emphasis on the response and effects of corticosteroids. Annu. Rev. Fish Dis. 1, 3-26 (1991).

6. Cole, S. W. et al. Transcriptional modulation of the developing immune system by early life social adversity. Proc. Natl. Acad. Sci. USA 109, 20578-20583 (2012).

7. Irwin, M. R. \& Cole, S. W. Reciprocal regulation of the neural and innate immune systems. Nat. Rev. Immunol. 11, 625-632 (2011).

8. Bekhbat, M., Rowson, S. A. \& Neigh, G. N. Checks and balances: the glucocorticoid receptor and NF-KB in good times and bad. Front. Neuroendocrinol. https://doi.org/10.1016/j.yfrne.2017.05.001 (2017).

9. Korytáŕ, T. et al. Adverse husbandry of maraena whitefish directs the immune system to increase mobilization of myeloid cells and proinflammatory responses. Front. Immunol. 7, (2016).

10. Maule, A. G., Tripp, R. A., Kaattari, S. L. \& Schreck, C. B. Stress alters immune function and disease resistance in chinook salmon (Oncorhynchus tshawytscha). J. Endocrinol. 120, 135-142 (1989).

11. Ainsworth, A. J., Dexiang, C., Waterstrat, P. R. \& Greenway, T. Effect of temperature on the immune system of channel catfish (Ictalurus punctatus)-I. Leucocyte distribution and phagocyte function in the anterior kidney at 10 degrees C. Comp. Biochem. Physiol. A Comp. Physiol. 100, 907-12 (1991). 
12. $\mathrm{Xu}, \mathrm{C}$. et al. Histological and transcriptomic responses of two immune organs, the spleen and head kidney, in Nile tilapia (Oreochromis niloticus) to long-term hypersaline stress. Fish Shellfish Immunol. 76, 48-57 (2018).

13. Barton, B. A. Stress in fishes: a diversity of responses with particular reference to changes in circulating corticosteroids. Integr. Comp. Biol. 42, 517-525 (2006).

14. Rebl, A. \& Goldammer, T. Under control: the innate immunity of fish from the inhibitors' perspective. Fish Shellfish Immunol. 77, 328-349 (2018).

15. Tort, L. Stress and immune modulation in fish. Dev. Comp. Immunol. 35, 1366-1375 (2011).

16. Pagniello, K. B., Bols, N. C. \& Lee, L. E. J. Effect of corticosteroids on viability and proliferation of the rainbow trout monocyte/ macrophage cell line, RTS11. Fish Shellfish Immunol. 13, 199-214 (2002).

17. MacKenzie, S. et al. Transcriptional analysis of LPS-stimulated activation of trout (Oncorhynchus mykiss) monocyte/macrophage cells in primary culture treated with cortisol. Mol. Immunol. 43, 1340-1348 (2006).

18. Khansari, A. R., Parra, D., Reyes-López, F. E. \& Tort, L. Modulatory in vitro effect of stress hormones on the cytokine response of rainbow trout and gilthead sea bream head kidney stimulated with Vibrio anguillarum bacterin. Fish Shellfish Immunol. 70, 736-749 (2017).

19. Castillo, J., Teles, M., Mackenzie, S. \& Tort, L. Stress-related hormones modulate cytokine expression in the head kidney of gilthead seabream (Sparus aurata). Fish Shellish Immunol. 27, 493-499 (2009).

20. Thorgaard, G. H. et al. Status and opportunities for genomics research with rainbow trout. Comp. Biochem. Physiol. B Biochem. Mol. Biol. 133, 609-646 (2002).

21. Chen, Z. et al. Selection for upper thermal tolerance in rainbow trout (Oncorhynchus mykiss Walbaum). J. Exp. Biol. https://doi. org/10.1242/jeb.113993 (2015).

22. Borchel, A., Verleih, M., Rebl, A. \& Goldammer, T. Identification of genes involved in cold-shock response in rainbow trout (Oncorhynchus mykiss). J. Genet. https://doi.org/10.1007/s12041-017-0811-x (2017).

23. Verleih, M. et al. Impact of thermal stress on kidney-specific gene expression in farmed regional and imported rainbow trout. Mar. Biotechnol. 17, 576-592 (2015)

24. Akbarzadeh, A. et al. Developing specific molecular biomarkers for thermal stress in salmonids. BMC Genom. 19, 749 (2018).

25. Lewis, J. M., Hori, T. S., Rise, M. L., Walsh, P. J. \& Currie, S. Transcriptome responses to heat stress in the nucleated red blood cells of the rainbow trout (Oncorhynchus mykiss). Physiol. Genom. 42, 361-373 (2010).

26. Vornanen, M., Hassinen, M., Koskinen, H. \& Krasnov, A. Steady-state effects of temperature acclimation on the transcriptome of the rainbow trout heart. Am. J. Physiol. Regul. Integr. Comp. Physiol. 289, R1177-R1184 (2005).

27. Rebl, A. et al. Transcriptome profiling of gill tissue in regionally bred and globally farmed rainbow trout strains reveals different strategies for coping with thermal stress. Mar. Biotechnol. (NY) 15, 445-460 (2013).

28. Tomalty, K. M. H. et al. Transcriptional response to acute thermal exposure in juvenile chinook salmon determined by RNAseq. G3 5, 1335-49 (2015).

29. Narum, S. R. \& Campbell, N. R. Transcriptomic response to heat stress among ecologically divergent populations of redband trout. BMC Genom. 16, 103 (2015).

30. Wang, Y. et al. Effects of heat stress on respiratory burst, oxidative damage and SERPINH1 (HSP47) mRNA expression in rainbow trout Oncorhynchus mykiss. Fish Physiol. Biochem. 42, 701-710 (2016).

31. Ellis, T. et al. The relationships between stocking density and welfare in farmed rainbow trout. J. Fish Biol. 61, 493-531 (2002).

32. North, B., Turnbull, J. \& Ellis, T. The impact of stocking density on the welfare of rainbow trout (Oncorhynchus mykiss). Aquaculture 255, 466-479 (2006).

33. Person-Le Ruyet, J. et al. Combined effects of water quality and stocking density on welfare and growth of rainbow trout (Oncorhynchus mykiss). Aquat. Living Resour. 21, 185-195 (2008).

34. Trenzado, C. E., Morales, A. E. \& de la Higuera, M. Physiological effects of crowding in rainbow trout, Oncorhynchus mykiss, selected for low and high stress responsiveness. Aquaculture 258, 583-593 (2006).

35. Yarahmadi, P., Miandare, H. K., Hoseinifar, S. H., Gheysvandi, N. \& Akbarzadeh, A. The effects of stocking density on hematoimmunological and serum biochemical parameters of rainbow trout (Oncorhynchus mykiss). Aquac. Int. 23, 55-63 (2014).

36. Rebl, A. et al. Microarray-predicted marker genes and molecular pathways indicating crowding stress in rainbow trout (Oncorhynchus mykiss). Aquaculture 473, 355-365 (2017).

37. Mazur, C. F. \& Iwama, G. K. Effect of handling and stocking density on hematocrit, plasma cortisol, and survival in wild and hatchery-reared chinook salmon (Oncorhynchus tshawytscha). Aquaculture 112, 291-299 (1993).

38. Wagner, E. J., Bosakowski, T. \& Intelmann, S. Combined effects of temperature and high pH on mortality and the stress response of rainbow trout after stocking. Trans. Am. Fish. Soc. 126, 985-998 (2004).

39. Liu, F.-G., Yang, S.-D. \& Chen, H.-C. Effect of temperature, stocking density and fish size on the ammonia excretion in palmetto bass (Morone saxatilis $\times$ M. chrysops). Aquac. Res. 40, 450-455 (2009).

40. Mijošek, T. et al. Evaluation of multi-biomarker response in fish intestine as an initial indication of anthropogenic impact in the aquatic karst environment. Sci. Total Environ. 660, 1079-1090 (2019).

41. McBryan, T. L., Anttila, K., Healy, T. M. \& Schulte, P. M. Responses to temperature and hypoxia as interacting stressors in fish: implications for adaptation to environmental change. Integr. Comp. Biol. 53, 648-659 (2013).

42. Woynarovich, A., Hoitsy, G. \& Moth-Poulsen, T. Small-scale rainbow trout farming. FAO fisheries and aquaculture technical paper No. 561 (2011)

43. Djordjevic, B. et al. Modulation of splenic immune responses to bacterial lipopolysaccharide in rainbow trout (Oncorhynchus mykiss) fed lentinan, a beta-glucan from mushroom Lentinula edodes. Fish Shellfish Immunol. 26, 201-209 (2009).

44. Hadidi, S., Glenney, G. W., Welch, T. J., Silverstein, J. T. \& Wiens, G. D. Spleen size predicts resistance of rainbow trout to Flavobacterium psychrophilum challenge. J. Immunol. 180, 4156-4165 (2008).

45. Purcell, M. K., Kurath, G., Garver, K. A., Herwig, R. P. \& Winton, J. R. Quantitative expression profiling of immune response genes in rainbow trout following infectious haematopoietic necrosis virus (IHNV) infection or DNA vaccination. Fish Shellfish Immunol. 17, 447-462 (2004).

46. Abdel-Aziz, E.-S.H., Abdu, S. B. S., El-Sayed Ali, T., Ali, T.E.-S. \& Fouad, H. F. Haemopoiesis in the head kidney of tilapia, Oreochromis niloticus (Teleostei: Cichlidae): a morphological (optical and ultrastructural) study. Fish Physiol. Biochem. 36, 323-336 (2010).

47. Lu, X.-J., Chen, Q., Rong, Y.-J. \& Chen, J. Mobilisation and dysfunction of haematopoietic stem/progenitor cells after Listonella anguillarum infection in ayu Plecoglossus altivelis. Sci. Rep. 6, 28082 (2016).

48. Havixbeck, J. \& Barreda, D. Neutrophil development, migration, and function in teleost fish. Biology 4, 715-734 (2015).

49. Trust, T. J., Courtice, I. D., Khouri, A. G., Crosa, J. H. \& Schiewe, M. H. Serum resistance and hemagglutination ability of marine vibrios pathogenic for fish. Infect. Immun. 34, 702-707 (1981).

50. Ourth, D. D. \& Wilson, E. A. Bactericidal serum response of the channel catfish against gram-negative bacteria. Dev. Comp. Immunol. 6, 579-583 (1982).

51. Davis, A. K., Maney, D. L. \& Maerz, J. C. The use of leukocyte profiles to measure stress in vertebrates: a review for ecologists. Funct. Ecol. 22, 760-772 (2008).

52. Korytár, T. et al. Novel insights into the peritoneal inflammation of rainbow trout (Oncorhynchus mykiss). Fish Shellfish Immunol. 35, 3-10 (2013). 
53. Gelling, M., Johnson, P. J., Moorhouse, T. P. \& Macdonald, D. W. Measuring animal welfare within a reintroduction: An assessment of different indices of stress in water voles Arvicola amphibius. PLoS One 7, e41081 (2012).

54. Barnham, C. \& Baxter, A. Condition factor, K, for salmonid fishwind river. Fish. Notes 1-3 (1998).

55. Blom, J. H., Lee, K. J., Rinchard, J., Dabrowski, K. \& Ottobre, J. Reproductive efficiency and maternal-offspring transfer of gossypol in rainbow trout (Oncorhynchus mykiss) fed diets containing cottonseed meal. J. Anim. Sci. 79, 1533 (2001).

56. Wells, R. M. G. \& Weber, R. E. Is there an optimal haematocrit for rainbow trout, Oncorhynchm mykiss (Walbaum)? An interpretation of recent data based on blood viscosity measurements. J. Fish Biol. 38, 53-65 (1991).

57. Aerts, J. et al. Scales tell a story on the stress history of fish. PLoS ONE 10, e0123411 (2015).

58. Barton, B. A. Salmonid fishes differ in their cortisol and glucose responses to handling and transport stress. N. Am. J. Aquac. 62, $12-18(2000)$.

59. Weber, J.-M. \& Shanghavi, D. S. Regulation of glucose production in rainbow trout: role of epinephrine in vivo and in isolated hepatocytes. Am. J. Physiol. Integr. Comp. Physiol. 278, R956-R963 (2000).

60. Iwama, G. K., Vijayan, M. M., Forsyth, R. B. \& Ackerman, P. A. Heat shock proteins and physiological stress in fish. Am. Zool. 39, 901-909 (1999).

61. Martinez-Porchas, M., Martinez-Cordova, L. T. \& Ramos-Enriquez, R. Cortisol and glucose : reliable indicators of fish stress?. J. Aquat. Sci. 4, 158-178 (2009).

62. Gräns, A. et al. Stunning fish with $\mathrm{CO}_{2}$ or electricity: contradictory results on behavioural and physiological stress responses. Animal 10, 294-301 (2016).

63. Ortuño, J., Esteban, M. A. \& Meseguer, J. Effects of phenoxyethanol on the innate immune system of gilthead seabream (Sparus aurata L.) exposed to crowding stress. Vet. Immunol. Immunopathol. 89, 29-36 (2002).

64. Das, C., Thraya, M. \& Vijayan, M. M. Nongenomic cortisol signaling in fish. Gen. Comp. Endocrinol. https://doi.org/10.1016/j. ygcen.2018.04.019 (2018).

65. Jeffries, K. M. et al. Consequences of high temperatures and premature mortality on the transcriptome and blood physiology of wild adult sockeye salmon (Oncorhynchus nerka). Ecol. Evol. 2, 1747-1764 (2012).

66. Li, Y. et al. Transcriptome analysis provides insights into hepatic responses to moderate heat stress in the rainbow trout (Oncorhynchus mykiss). Gene 619, 1-9 (2017).

67. Jeffries, K. M., Hinch, S. G., Sierocinski, T., Pavlidis, P. \& Miller, K. M. Transcriptomic responses to high water temperature in two species of Pacific salmon. Evol. Appl. 7, 286-300 (2014).

68. Stefanovic, D. I. et al. Thermal stress and the heat shock response in embryonic and young of the year juvenile lake whitefish. Comp. Biochem. Physiol. A Mol. Integr. Physiol. 193, 1-10 (2016).

69. Rebl, A. et al. Gradual and acute temperature rise induces crossing endocrine, metabolic and immunological pathways in maraena whitefish (Coregonus maraena). Front. Genet. 9, 241 (2018).

70. Buckley, B. A., Gracey, A. Y. \& Somero, G. N. The cellular response to heat stress in the goby Gillichthys mirabilis: a cDNA microarray and protein-level analysis. J. Exp. Biol. 209, 2660-2677 (2006).

71. Quinn, N. L., McGowan, C. R., Cooper, G. A., Koop, B. F. \& Davidson, W. S. Ribosomal genes and heat shock proteins as putative markers for chronic, sublethal heat stress in Arctic charr: applications for aquaculture and wild fish. Physiol. Genom. 43, 1056-1064 (2011).

72. Quinn, N. L., McGowan, C. R., Cooper, G. A., Koop, B. F. \& Davidson, W. S. Identification of genes associated with heat tolerance in Arctic charr exposed to acute thermal stress. Physiol. Genom. 43, 685-696 (2011).

73. Anttila, K., Eliason, E. J., Kaukinen, K. H., Miller, K. M. \& Farrell, A. P. Facing warm temperatures during migration: cardiac mRNA responses of two adult Oncorhynchus nerka populations to warming and swimming challenges. J. Fish Biol. 84, 1439-1456 (2014).

74. Smith, T. R., Tremblay, G. C. \& Bradley, T. M. Characterization of the heat shock protein response of Atlantic salmon (Salmo salar). Fish Physiol. Biochem. 20, 279-292 (1999).

75. Moniruzzaman, M., Ghosal, I., Das, D. \& Chakraborty, S. B. Melatonin ameliorates H2O2-induced oxidative stress through modulation of Erk/Akt/NFkB pathway. Biol. Res. 51, 17 (2018).

76. Sun, P., Bao, P. \& Tang, B. Transcriptome analysis and discovery of genes involved in immune pathways in large yellow croaker (Larimichthys crocea) under high stocking density stress. Fish Shellfish Immunol. 68, 332-340 (2017).

77. Köbis, J. M. et al. Comprehensive and comparative transcription analyses of the complement pathway in rainbow trout. Fish Shellfish Immunol. 42, 98-107 (2015).

78. Nakao, M., Tsujikura, M., Ichiki, S., Vo, T. K. \& Somamoto, T. The complement system in teleost fish: progress of post-homologhunting researches. Dev. Comp. Immunol. 35, 1296-1308 (2011).

79. Ellsaesser, C. F. \& Clem, L. W. Haematological and immunological changes in channel catfish stressed by handling and transport. J. Fish Biol. 28, 511-521 (1986).

80. Ainsworth, A. J., Dexiang, C. \& Waterstrat, P. R. Changes in peripheral blood leukocyte percentages and function of neutrophils in stressed channel catfish. J. Aquat. Anim. Health 3, 41-47 (1991).

81. Köllner, B., Fischer, U., Rombout, J. H. W. M., Taverne-Thiele, J. J. \& Hansen, J. D. Potential involvement of rainbow trout thrombocytes in immune functions: a study using a panel of monoclonal antibodies and RT-PCR. Dev. Comp. Immunol. 28, 1049-1062 (2004).

82. Rebl, A. et al. Identification of differentially expressed protective genes in liver of two rainbow trout strains. Vet. Immunol. Immunopathol. 145, 305-315 (2012).

83. Köbis, J. M., Rebl, A., Kühn, C. \& Goldammer, T. Comparison of splenic transcriptome activity of two rainbow trout strains differing in robustness under regional aquaculture conditions. Mol. Biol. Rep. 40, 1955-1966 (2013).

84. Brietzke, A. et al. Aeromonas salmonicida infection only moderately regulates expression of factors contributing to toll-like receptor signaling but massively activates the cellular and humoral branches of innate immunity in rainbow trout (Oncorhynchus mykiss). J. Immunol. Res. 2015, 1-16 (2015).

85. Zante, M. D., Borchel, A., Brunner, R. M., Goldammer, T. \& Rebl, A. Cloning and characterization of the proximal promoter region of rainbow trout (Oncorhynchus mykiss) interleukin-6 gene. Fish Shellfish Immunol. 43, 249-256 (2014).

86. Rivera, L., López-Patiño, M. A., Milton, D. L., Nieto, T. P. \& Farto, R. Effective qPCR methodology to quantify the expression of virulence genes in Aeromonas salmonicida subsp. salmonicida. J. Appl. Microbiol. 118, 792-802 (2015).

87. Smyth, G.K. Limma: linear models for microarray data. In: Bioinformatics and Computational Biology Solutions Using R and Bioconductor (eds. Gentleman, R., Carey, V., Dudoit, S., Irizarry, R. \& Huber, W.) 397-420 (Springer, Berlin, 2005).

88. Benjamini, Y. \& Hochberg, Y. Controlling the false discovery rate: a practical and powerful approach to multiple testing. J. R. Stat. Soc. Ser. B 57, 289-300 (1995).

89. Oliveros, J. C. VENNY. An interactive tool for comparing lists with venn diagrams. https://bioinfogp.cnb.csic.es/tools/venny/ index.html. Bioinfogp.Cnb.Csic.Es/Tools/Venny/Index.Html https://bioinfogp.cnnb.csic.es/tools/venny/index.ht (2007). https:// doi.org/10.1017/S0266267108002022

90. Bowers, R. M., Lapatra, S. E. \& Dhar, A. K. Detection and quantitation of infectious pancreatic necrosis virus by real-time reverse transcriptase-polymerase chain reaction using lethal and non-lethal tissue sampling. J. Virol. Methods 147, 226-234 (2008). 


\section{Acknowledgements}

We are indebted to B. Schöpel, I. Hennings, and L. Falkenthal for expert technical assistance and we acknowledge A. Tuchscherer for providing statistical support (SAS software). S. Rüberg (Miltenyi Biotec GmbH, Bergisch Gladbach, Germany) is highly acknowledged for hybridising the salmon microarrays and supporting the submission of the data sets to GEO. We thank B. Köllner (Friedrich-Loeffler-Institut, Riems, Germany) for providing rainbow trout-specific antibodies. The European Fisheries Fund (EFF) and the Ministry of Agriculture, the Environment and Consumer Protection Mecklenburg-Western Pomerania, Germany (Pilot project 'Born-Forelle VI-560/7308-4') as well as the Ministry of Education, Youth and Sports of the Czech Republic, Project CENAKVA (LM2018099) and NAZV project (QK1820354) financed this study. The publication of this article was funded by the Open-Access Fund of the FBN.

\section{Author contributions}

TG, MV, TK, AR designed the study. RB organised the production of fish and measured abiotic parameters. TK performed FACS and in vitro analyses. MV performed qPCR analyses and plasma-parameter measurements. JES investigated bacterial growth rates. AR, AB, MV analysed transcriptomic data. All authors were involved in sampling and in the interpretation of experimental data. AR wrote and MV, TK edited the manuscript. All authors have read and approved the final article.

\section{Funding}

Open Access funding provided by Projekt DEAL.

\section{Competing interest}

The authors declare no competing interests.

\section{Additional information}

Supplementary information is available for this paper at https://doi.org/10.1038/s41598-020-71852-8.

Correspondence and requests for materials should be addressed to M.V.

Reprints and permissions information is available at www.nature.com/reprints.

Publisher's note Springer Nature remains neutral with regard to jurisdictional claims in published maps and institutional affiliations.

(c) (i) Open Access This article is licensed under a Creative Commons Attribution 4.0 International License, which permits use, sharing, adaptation, distribution and reproduction in any medium or format, as long as you give appropriate credit to the original author(s) and the source, provide a link to the Creative Commons licence, and indicate if changes were made. The images or other third party material in this article are included in the article's Creative Commons licence, unless indicated otherwise in a credit line to the material. If material is not included in the article's Creative Commons licence and your intended use is not permitted by statutory regulation or exceeds the permitted use, you will need to obtain permission directly from the copyright holder. To view a copy of this licence, visit http://creativecommons.org/licenses/by/4.0/.

(C) The Author(s) 2020 